\title{
Multi-Objective Optimization of Microemulsion Flooding for Chemical Enhanced Oil Recovery
}

\author{
Mohammad Saber Karambeigi, Ali Haghighi Asl and Masoud Nasiri \\ Faculty of Chemical, Gas and Petroleum Engineering, Semnan University, Semnan 35195-363 - Iran \\ e-mail: mnasiri@semnan.ac.ir \\ *Corresponding author
}

\begin{abstract}
Microemulsion flooding is one of the most effective methods of Chemical Enhanced Oil Recovery (CEOR), particularly for the production of residual oil trapped in unconventional reservoirs. A critical step for successful application of this technique is to achieve a suitable formulation. Previous studies have almost focused on the technical aspects while considering both practical and economic matters as conflicting objectives have been neglected. In the present paper, the formulation of microemulsion is optimized based on the trade-off between scientific and financial responses using a hybrid workflow in which experimental design and artificial intelligence methodologies are composed. To appraise the efficiency of developed algorithm, a challenge case study is first evaluated and compared to previous approaches. Thereafter, the second case is examined in which a newly developed formulation of microemulsion for high temperature carbonate reservoirs is optimized. The outcomes of this multi-attribute workflow are compared to a single-objective algorithm. The results indicate the outstanding performance of the proposed approach for multi-objective optimization of microemulsion formulation. Eventually, the possible concerns regarding the application of microemulsion flooding in unconventional reservoirs are discussed.
\end{abstract}

\section{INTRODUCTION}

An immense amount of oil is remained unrecovered in the reservoirs after primary and secondary mechanisms of oil recovery. Generally, it exceeds more than half of the Original Oil in Place (OOIP) in almost cases [1, 2]. This considerable potential is of great interest for Enhanced Oil Recovery (EOR) methods which fall into three main categories: thermal, gas and chemical methods. Generally, they involve the injection of fluids into the reservoir to generate favorable fluid properties or interfacial conditions, overcoming forces trapping the oil and boosting oil production substantially [3-5].

Microemulsion flooding is one of the high-performance techniques of Chemical Enhanced Oil Recovery (CEOR) methods. Not only does it have different advantages such as ultra low Interfacial Tension (IFT) and/or better sweep efficiency compared to water or surfactant flooding but it also can overcome some important drawbacks of conventional CEOR processes; for instance, high adsorption of surfactants and difficulties with control over in situ gelation of polymers in the reservoirs. The results of experimental as well as modeling studies demonstrate microemulsion flooding is one of the most promising solutions to achieve incremental oil recovery [6-8].

The optimization of influential parameters is of vital importance in the successful application of any CEOR technique particularly microemulsion flooding because not only does it improve its efficiency, but it also reduces the chemical costs and their possible harmful environmental impacts [9-11] owing to the fact microemulsion flooding is a complex and expensive operation [12]. For this purpose, different methodologies have been proposed in the literature.

A reservoir simulator with an economic model was used by $\mathrm{Wu}$ et al. [13] to optimize a chemical flood of a typical sandstone onshore oilfield. Zerpa et al. [10] developed a 
surrogate-based optimization methodology to estimate the optimal values for a set of design variables (concentration and slug size of chemicals). Then, Carrero et al. [11] employed this approach to study a global sensitivity analysis. Anderson et al. [14] optimized chemical flooding for a mixed-wet dolomite reservoir using sensitivity analysis of key parameters. Prasanphanich et al. [15] optimized Net Present Value (NPV) of chemical flooding using in-house simulators coupled with experimental design methodology. Douarche et al. [16] utilized response surface methodology to develop a surrogate model by which oil recovery from a surfactant-polymer flood was estimated and optimized. AlSofi and Blunt [17] simulated rheological behavior of polymer as a non-Newtonian fluid using streamline approach to evaluate polymer-flooding design.

Previous studies thoroughly discussed and optimized the technical aspects of CEOR approaches. They have mostly considered oil recovery or NPV as a singleobjective optimization process. Seldom have they paid attention to both practical and economic features. When a CEOR operation is going to be efficiently implemented, different aspects of technical and economic factors should be simultaneously analyzed. In this regard, the prediction of optimum values for control variables considering the multiple conflicting criteria is known as multi-objective optimization. In such problems, optimal decisions need to be taken in the presence of trade-off between two or more competing objectives $[18,19]$. Methodologies for multi-attribute optimization of CEOR or even other EOR approaches have rarely been reported in the literature.

In this study, a robust algorithm for multi-criteria optimization is developed based on the design of experiments and artificial intelligence techniques. The proposed workflow is comprised of two main stages: modeling and then optimization. The modeling operation establishes a mathematical relationship between design variables and corresponding responses of the process. For this purpose, Response Surface Methodology (RSM) is employed to attain precise objective functions. In the next stage, Particle Swarm Optimization (PSO) is coupled with Fuzzy Logic (FL), generating a multi-criteria optimization methodology to find the best solution of the problem. To confirm the efficacy of this algorithm, it is applied for modeling and multi-objective optimization of microemulsion flooding in different two case studies.

\section{BACKGROUND}

\subsection{The Advantages of Microemulsion Flooding}

Demonstrated the outstanding performance of CEOR processes have the results of numerous experimental and numerical studies. Consequently, many thriving CEOR projects have been reported worldwide. Although there is no doubt about the inherent efficiency of CEOR techniques [20-23], several issues have threaten its successful application in unconventional resources, such as high price of chemicals, harsh condition of oilfields, and possible formation damage.

In recent years, the shadow of bad economic conditions and low price of oil have fallen across the development of EOR projects. It matters a great deal to CEOR techniques because they are known as expensive approaches among other EOR operations. Therefore, decision makers should have multiple perspectives rather than single-objective insight in which one aspect (e.g. technical) is considered regardless of other features (e.g. economic). In this atmosphere, the application of multi-purpose algorithms paves the way for the optimization of control variables in terms of conflicting objectives, improving the efficacy of the operation and simultaneously managing the limited budget. In this paper, a workflow for multi-attribute optimization was successfully proposed in two case studies of microemulsion flooding. The application of this efficient methodology would be extended beyond different cases of CEOR or even other EOR techniques if sufficient data can be gathered.

The next concern is about the development of unconventional reservoirs. High potential of CEOR processes are always attractive to such reservoirs where thermal stability and ionic compatibility of chemicals are permanent restrictions. This article deals with microemulsions which are defined as thermodynamic-stable dispersion of an immiscible liquid into another one. The feasibility of the successful application of microemulsions in high temperature reservoirs can be vindicated by considering two concepts: spontaneous formation and thermodynamic stability of microemulsions. According to the second law of thermodynamic, the formation of microemulsions is modeled using Gibbs free energy:

$$
\Delta G_{F}=\gamma \Delta A-T \Delta S,
$$

where $\Delta G_{F}$ is the change in Gibbs free energy, $\gamma$ is IFT, $\Delta A$ is the change in surface area $(A), T$ is temperature and $\Delta S$ is the variation of configurational entropy [24].

A colloidal dispersion is formed spontaneously when the variations of Gibbs free energy become negative. To fulfill the conditions, ultra-low interfacial tension due to the presence of an appropriate surfactants required [25]. Consequently, $\gamma \Delta A<-T \Delta S$ and then $\Delta G_{F}<0$. Thus, the surfactant plays the crucial role for the microemulsion formation and the highenergy external sources for mixing two separate phases does not require. It saves the energy and therefore reduces the expenditure of formulation compared to macroemulsions and nanoemulsions which usually require external sources of energy such as ultrasonic waves or stirring [26]. 
Accordingly, thermodynamic stability means the free energy of microemulsions is lower than the free energy of the reference state (oil and water phases). It indicates the system tends to continue its stable position whenever the thermodynamic conditions (e.g. temperature) remain unchanged. When a microemulsion is formed in a particular temperature, the thermal stability of the mixture is guaranteed until the temperature is kept constant. Therefore, this concept can be used as an efficient mechanism to retain the unlimited stability of microemulsion slug at high temperature. In contrast, macroemulsions and nanoemulsions are thermodynamically unstable although they can be kinetically stable which defines as their tendency to persist in a meta-stable position for long time rather than a limitless period [27].

For CEOR purposes, injection fluids should be stable for at least several months. The injection of a thermodynamically stable microemulsion ensures that the chemicals can keep their original properties and work with highest efficiency during the time interval between injection and production wells. However, the instability always threatens other types of dispersions. This idea has been successfully developed in our previous study in which the formulations of the microemulsions were stable for several months while the phase behavior, characterization of optimum mixture, and oil recovery experiments in carbonate rocks were being done [28].

Another restriction of CEOR applications in unconventional reservoirs is the ionic compatibility between the chemicals and sea water or formation water. The mixture of surfactant should be compatible with the composition of these samples of water.

The last point is the evaluation of formation damage due to the injection of microemulsions as they are colloidal dispersions. Insofar as the microemulsions contain the droplets of the interior phase dispersed in the continuous phase, the size of particles should be set so that they can prevent the plugging of pores and throats which causes the formation damage.

\subsection{Response Surface Methodology}

RSM is comprised of a collection of statistical and mathematical techniques. It can be used when several associated factors influence a corresponding response or a set of responses in a process. Compared to trial-and-error approaches of experimental design in which a factor is changed while others are constant, RSM has different advantages. The effects of factors on the process response(s) can be studied through varying the levels of factors simultaneously. Hence, not only does RSM provide the optimum experimental design to cover all the sampling space with minimum required experiments (saving time and the budget) but it also can fit an appropriate model to the data
[29]. In the other words, it can develop a functional relationship between a number of related parameters (as the inputs of the process) and the response(s) through statistically analyzing their interactions. Furthermore, it can be applied for the optimization of the process to determine its best performance. Therefore, it is an efficient protocol for Design of Experiments (DOE) [29-33].

\subsection{Artificial Neural Network}

Artificial Neural Network (ANN) is an information processing paradigm which is inspired by biological neural networks. It consists of highly inter-connected elements that are known as neurons [34]. As a parallel, distributive and adaptive system, it can be effectively applied in complex and non-linear problems in different engineering disciplines [35-37]. Nowadays, ANN is a computational tool in petroleum engineering studies because not only it is a model-free function predictor but also it does not require any detailed knowledge regarding the process [38-40].

Multi-Layer Perceptron (MLP) network in accompaniment with back propagation training algorithm is known as the most popular paradigm for the construction of the network. MLP structure comprises different layers (input, hidden and output). Different number of neurons is placed on each layer. The connectivity between each neuron of the current layer and those on the proceeding layer is established through direct links that have their own weights. In the training phase, these weights are changed to satisfy the training goal. The output layer collects the received signals from previous layers and creates the response of the network; in other words, ANN models the process. Theoretical outlines of ANN have been discussed elsewhere [41].

\subsection{Particle Swarm Optimization}

Particle Swarm Optimization (PSO) was introduced by Kennedy and Eberhart in 1995 [42]. The idea was originally derived from mimicking social behaviors exhibited by group animals such as bird flocking and fish schooling. It is a population-based stochastic search like other biologically inspired optimization paradigms [43]. PSO is an attractive optimization methodology because not only can it be simply implemented with low computational efforts owing to the fact that there are few parameters to be adjusted, but it also adopts real numbers as particles; in other words, it does not need binary encoding or evolutionary operations which are required for Genetic Algorithm (GA). Furthermore, PSO utilizes collaborative approach (particles have memory to maintain knowledge of appropriate solutions) compared to GA in which a competitive one is used. Thus, PSO is very successful to solve a wide variety of problems of diverse engineering as well as computational science in continuous search space [44-46]. 
TABLE 1

General properties of chemicals in two case studies.

\begin{tabular}{l|l|l|l|l}
\hline \multirow{2}{*}{ Chemical } & \multicolumn{2}{|c|}{ Case study 1 } & \multicolumn{2}{c}{ Case study 2} \\
\cline { 2 - 5 } & Name & Cost & Name & Cost \\
\hline Surfactant & Alkyl polyglicoside (APG) & $1.6 \$ / \mathrm{L}$ & Polysorbate 80 & - \\
\hline Co-surfactant & Glyceryl monooleate & $2.0 \$ / \mathrm{kg}$ & - & \\
\hline Co-solvent & - & - & Ethanol & $0.62 \$ / \mathrm{L}$ \\
\hline Oleic phase & Palm kernel oil & $1.2 \$ / \mathrm{L}$ & Biodiesel & $0.94 \$ / \mathrm{L}$ \\
\hline
\end{tabular}

TABLE 2

Domain of different parameters in the original dataset of case study 1 .

\begin{tabular}{l|l|l|l|l|l|l}
\hline Parameter & Type & Symbol/Abb. & Min & Max & Mean & Standard deviation \\
\hline Surfactant concentration (wt\%) & Input & $C_{A P G}$ & 0.5 & 2.0 & 1.25 & 0.56 \\
\hline Salinity (wt\%) & Input & $S$ & 1 & 12 & 6.20 & 3.98 \\
\hline Co-surfactant concentration (wt\%) & Input & $C_{G M}$ & 0.5 & 4.0 & 2.25 & 1.15 \\
\hline Water content (wt\%) & Input & W & 82 & 98 & 90.30 & 4.18 \\
\hline Interfacial tension (mN/m) & Output & IFT & 0.0002 & 11.2530 & 0.58 & 1.97 \\
\hline Recovery factor (\%) & Output & RF & 63.2 & 71.8 & 67.55 & 1.89 \\
\hline
\end{tabular}

PSO uses a set of search points as particles in a population which is known as swarm. Two variables characterize the particles: the particle position $(x)$ which is representative of a potential solution to the problem and particle velocity $(v)$. It is initiated with a swarm of particles as random solutions distributed in the search space. Each particle moves through search space and compares its fitness value at the current position to the best fitness value so far attained. The best solution so far achieved by a particle is known as the personal best, or pbest. Accordingly, when PSO proceeds, global best or gbest is defined as the best global experience among all of the pbest positions achieved so far. The gbest is the final solution of the optimization problem. The stopping criterion can be the number of maximum iterations which is defined by user.

The definitions of pbest and gbest are employed to update the $i$ th particle velocity in the $d$ th dimension:

$$
\begin{aligned}
v_{i d}^{t+1}=w v_{i d}^{t}+ & C_{1} \operatorname{rand}_{(0,1)\left(\text { pbest }_{i d}-x_{i d}^{t}\right)}+C_{2} \operatorname{rand}(0,1)\left(\text { gbest }_{i d}-x_{i d}^{t}\right),
\end{aligned}
$$

where $w$ is inertia weight factor (controlling the effect of previous velocities on the current velocity), $C_{1}$ and $C_{2}$ coefficients are acceleration constants which help particles to accelerate towards favorable areas of the search space. The function of $\operatorname{rand}(0,1)$ generates a random number between 0 and 1 .
According to the updated velocity (Eq. 2), each particle repositions as follows:

$$
x_{i d}^{t+1}=x_{i d}^{t}+v_{i d}^{t+1} .
$$

\subsection{Fuzzy Logic}

The theory of fuzzy logic was introduced by Zadeh in 1965 [47]. It has been developed to facilitate approximate reasoning by which human expert's reasoning process is mimicked; in other words, a methodology to compute with words is provided using fuzzy logic. It is made up of the fuzzy sets [48]. In a crisp set (traditional Aristotle's logic), an object either belongs to this set or it does not. In a fuzzy set (Eq. 4), however, the transition from membership to nonmembership is gradual [49-52], that is to say any object belongs to a fuzzy set to a certain degree:

$$
F=\left\{x, \mu_{f}(x) \mid x \in X\right\},
$$

where $F$ is fuzzy set, $x$ is a generic element of $X$ as a space of points, and $\mu_{f}(x)$ is membership degree which quantifies the belonging grade of $x$ to the fuzzy set [53-55].

The concept of partial truth in fuzzy sets is represented by membership function which maps each object of $X$ to a membership value between 0 and 1 . There are different types of membership functions, such as Triangular, Trapezoidal and Gaussian. 
TABLE 3

Range of inputs and corresponding responses in case study 2 .

\begin{tabular}{l|l|l|l|l|l|l}
\hline Parameter & Type & Symbol/Abbreviation & Min & Max & Mean & Standard deviation \\
\hline Log $\left(C_{S}\right)(\mathrm{wt} \%)$ & Input & $C_{P S}$ & 0.0 & 1.0 & 0.5 & 0.22 \\
\hline Salinity $(\mathrm{wt} \%)$ & Input & $S$ & 0.0 & 10.0 & 5.0 & 2.24 \\
\hline Co-solvent content $(\mathrm{v} \%)$ & Input & $C_{E t h}$ & 0 & 20 & 10 & 4.47 \\
\hline Percentage of oleic phase (v\%) & Input & $\alpha$ & 10 & 50 & 30 & 8.94 \\
\hline Solubilization capacity $(\%)$ & Output & SC & 2.5 & 12.86 & 6.62 & 2.65 \\
\hline Cost of microemulsion production $(\$ / \mathrm{bbl})$ & Output & CoMP & 5.55 & 16.50 & 9.86 & 2.64 \\
\hline
\end{tabular}

\section{METHODOLOGY}

\subsection{Data}

Two case studies of microemulsion flooding were considered (Appendix A). The conditions and procedures to produce experimental data have been described elsewhere $[28,56]$. Table 1 contains the technical and economic information relevant to the chemicals used in their formulation. Moreover, the oil price was set to $\$ 50$.

\subsubsection{Case 1}

The first mixture was a triglyceride microemulsion [57] demonstrating the outstanding performance for CEOR applications in sandstones [58]. It was utilized in the first case study to confirm the efficiency of proposed algorithm via the comparison of results obtained by current methodology with those extracted from previous study [57]. The original dataset contained 160 data each of which comprised four inputs: the concentration of surfactant, salinity, co-surfactant concentration, and water content in the microemulsion phase. Interfacial Tension (IFT) of microemulsion and Recovery Factor (RF) were the outputs. The range of input and output parameters is presented in Table 2 .

\subsubsection{Case 2}

The second case study was a newly developed microemulsion formulation to be applied for CEOR in high temperature carbonate reservoirs [28]. Four inputs were included in each data: surfactant concentration, salinity, cosolvent concentration and volume percentage of initial oleic phase. The Solubilization Capacity (SC) of oil phase into aqueous phase and total Cost of Microemulsion Production (CoMP) were the corresponding responses. The domain of variables for this case study is tabulated in Table 3 .

\subsection{Algorithm for Modeling and Optimization}

An algorithm for multi-objective modeling and optimizing has been developed (Fig. 1). Two main stages are included in the procedure. The former provides objective functions through modeling of the microemulsion flooding using RSM and the latter optimizes the process as a multi-objective problem using PSO and FL. The detailed description of the algorithm is presented as follows:

\subsubsection{Process Modeling}

The current optimization algorithm requires precise objective functions. In this regard, the process was modeled to establish mathematical relationships between inputs and outputs of the process. For this purpose, RSM was employed by which statistically significant quadratic equations can be developed. In the first place, a series of $n$ experiments was designed. RSM consists of different approaches. The selected designs were dissimilar for two case studies. The former used D-optimal design while the latter utilized Central Composite Design (CCD). Both plans are the most popular RSM methods [59]. Considering four effective factors (Tabs. 2 and 3) with six center-point runs (to calculate experimental error and reproducibility of data), Doptimal design proposes 50 runs $(n=50)$ while CCD suggests a 30 -run plan $(n=30)$. In each run, an arrangement of four independent variables in different levels is set.

In the next step, the corresponding response (output) for each run should be provided. The routine approach to provide the response(s) is their measurement in the laboratory. For newly developed formulation of microemulsion in high temperature (case study 2), solubilization capacity of each run was already on offer from our previous study [28]. Accordingly, the cost of microemulsion formulation was calculated based on the information of Table 1. However, the pattern of experimental design (Doptimal) differs from that of original dataset (Factorial) [56] in case study 1 . The determination of $2 \times 50$ required responses experimentally necessitates an immense amount of time and considerable experimental expenditures. To try to deal with address this problem, a reliable solution was substituted whereby the responses were determined numerically via the development of a proxy model. For this purpose, artificial neural network as a data-dependent 


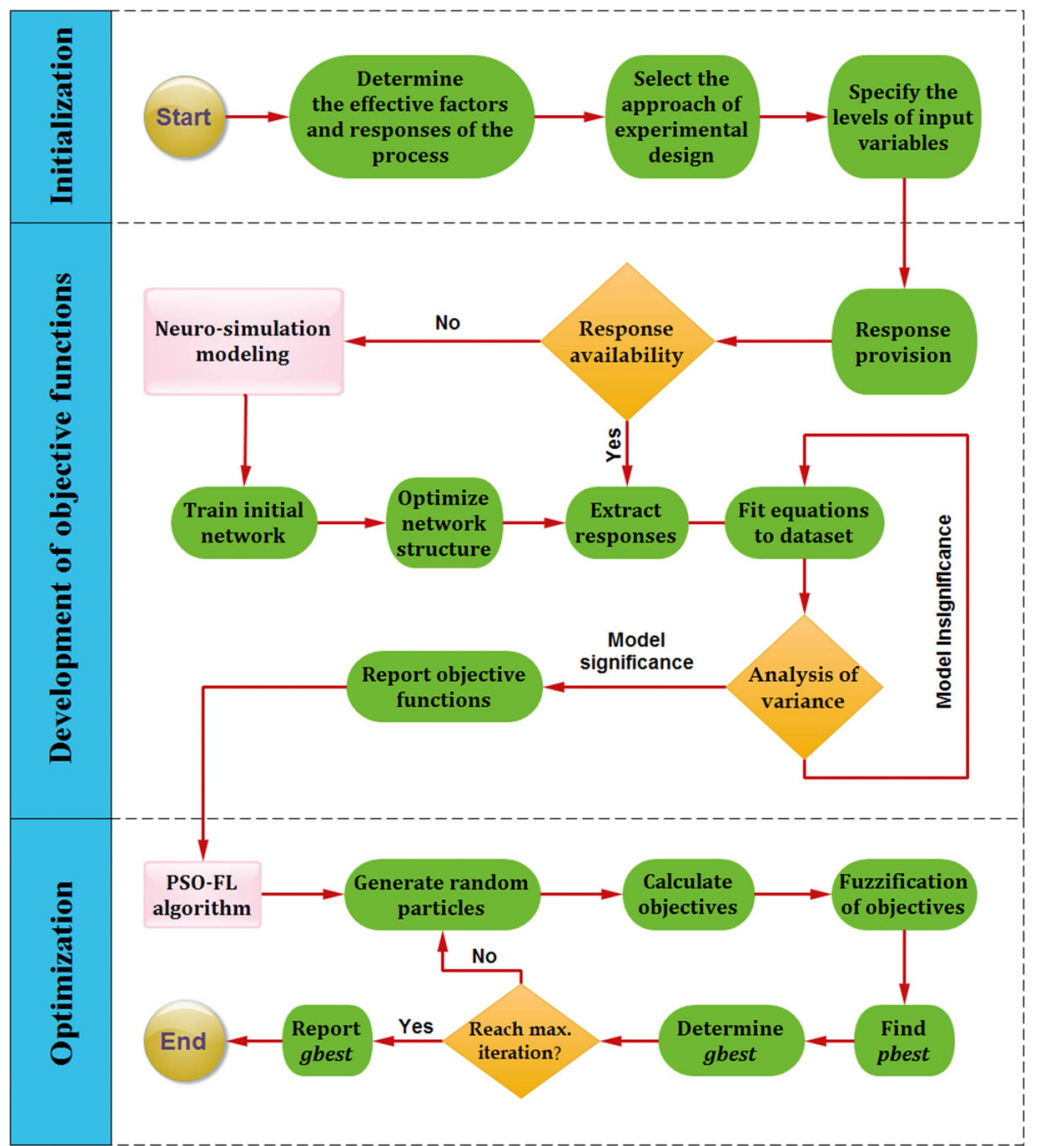

Figure 1

The workflow for modeling and multi-objective optimization.

paradigm was utilized for the development of a surrogate model. In other words, ANN acted as a numerical simulator for the extraction of 50 pairs of responses in D-optimal design.

To implement ANN modeling, the original dataset of experimental data was randomly divided into two separate datasets: training $(60 \%$ of the data) and evaluation (the remaining $40 \%$ ) datasets. 50 runs were put in a new dataset called testing. Inputs (four independent variables) and outputs (two dependent variables) of each individual data in different datasets were normalized using mean and standard deviation of variables. The process of ANN modeling was divided into three phases: training, generalization and operation.

The training phase was implemented to transfer expertise and derive functionality between inputs and outputs of the process which was generally unknown. For this end, a multilayer back propagation network was selected. This network consisted of 3 layers: input, one hidden and output. Tangent sigmoid and purelin types were assigned as transfer functions of hidden and output layers, respectively. Furthermore, Levenberg-Marquardt was the default training algorithm and the default number of neurons in hidden layer was two times the number of control variables, namely eight
neurons.The performance goal or the stopping criterion of this stage was Mean Square Error (MSE) of $1 \times 10^{-3}$. The training dataset was fed to this phase.

In the generalization phase, the optimum structure of the ANN was achieved based on the evaluation dataset. To that end, different number of neurons in the hidden layer from 1 to 15 as well as 10 training algorithms were evaluated which were as follows: Levenberg-Marquardt (trainnlm), BFGS quasi-Newton (trainbfg), Bayesian regularization (trainbr), Powell-Beale conjugate gradient (traincgb), FletcherPowell conjugate gradient (traincgf), Polak-Ribiere conjugate gradient (traincgp), Gradient descent with adaptive learning rate (traingda), Gradient descent with momentum (traingdm), Gradient descent with momentum and adaptive learning rate (traingdx).

Three statistical parameters of Mean Absolute Percentage Error (MAPE), Symmetric MAPE (SMAPE) and Root Mean Square Error (RMSE) quantified the accuracy of training and generalization phases:

$$
\text { MAPE }=\frac{100}{n} \sum_{i=1}^{n}\left|\frac{y_{p}-y_{e}}{y_{e}}\right|,
$$



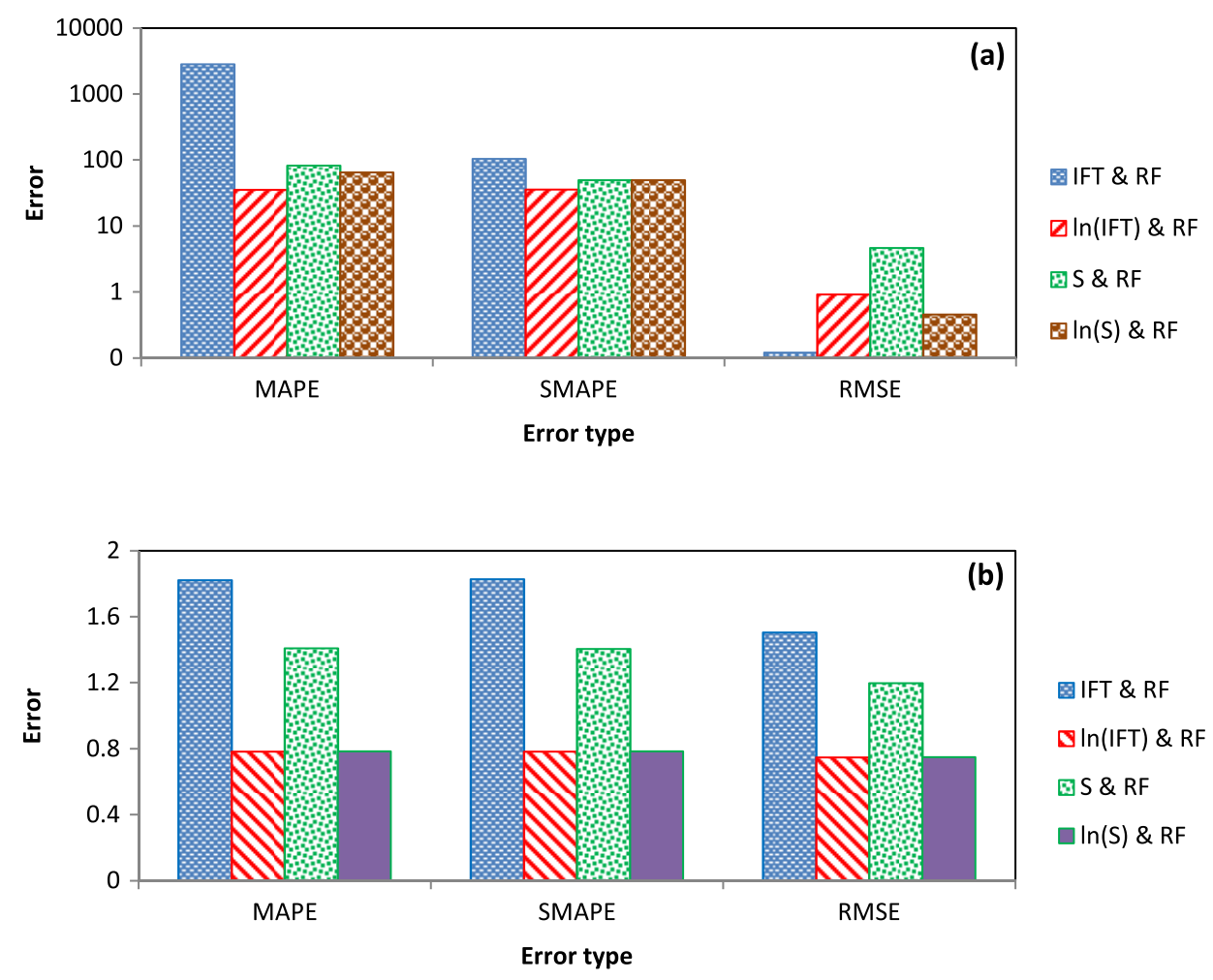

Figure 2

The effects of different transformations on the ANN prediction in training phase of case study 1: (a) interfacial tension and (b) recovery factor.

$$
\begin{gathered}
\mathrm{SMAPE}=\frac{100}{n} \sum_{i=1}^{n} \frac{\left|y_{p}-y_{e}\right|}{\left(\frac{\left|y_{p}\right|+\left|y_{e}\right|}{2}\right)}, \\
\mathrm{RMSE}=\left(\frac{1}{n} \sum_{i=1}^{n}\left(y_{p}-y_{e}\right)^{2}\right)^{1 / 2},
\end{gathered}
$$

where $n$ is the number of data in the dataset, $y_{p}$ is predicted response by $\mathrm{ANN}$ and $y_{e}$ is experimental data.

In the operation phase as the last step of surrogate modeling, ANN with optimized structure (the best performance) was utilized to extract the outputs of testing dataset. It was the end part of ANN modeling by which required responses of 50 runs in D-optimal design for case study 1 were provided.

There was another problem with the responses of case study 1 . They were not independent as whatever IFT is reduced RF increases. Therefore, they could not be considered as conflicting objectives in multi-attribute optimization methodology. To address this issue, RF was replaced with an economic output which was Chemical Efficiency (CE). It was defined as the total oil revenue calculated by RF at oil price of $\$ 50$ divided by the total cost of chemicals quantified based on the information of Table 1. IFT and CE were separately influenced by technical and economic features of the process, respectively. That is why they were taken into account as conflicting objectives for multi-attribute optimization of this case study.
For both case studies, responses were finally fed to RSM designs which analyzed the obtained data statistically through Analysis of Variance (ANOVA) to establish relationships between effective factors (inputs) and corresponding responses (outputs). In other words, RSM developed second-order equations as objective functions required for multipurpose optimization algorithm.

\subsubsection{Multi-Criteria Optimization Methodology}

Having objective functions obtained from previous stage, multi-objective optimization of microemulsion formulations was performed using PSO-FL methodology. For both case studies, low and high factorial points were selected as the extremes of each control variable in optimization process (Tab. 1) except to salinity that was set to a constant value because the salinity of the injection water in which chemicals are dissolved is constant. Insofar as the basic fluid for almost water-based EOR techniques is sea water, the salinity of both formulations in two case studies was fixed at $4.2 \mathrm{wt} \%$ which is the typical salinity of sea water [60]. Accordingly, the optimization goal was set to maximize the technical efficiency and minimize the cost of formulations, simultaneously.

In the first iteration, a swarm of 25 particles was randomly positioned in the search space. The constant inertia $(w)$ of 0.7298 and acceleration coefficients $\left(C_{1}\right.$ and $\left.C_{2}\right)$ of 1.49618 were assigned because empirical results have indicated that 
they help better convergent behavior [61]. Then, the components of velocity factor were initiated. Following this, the corresponding responses of each individual particle were calculated using objective functions.

To solve a multi-attribute problem, multiple objectives can be combined into one single-objective function. Moreover, finding pbest of each iteration necessitates the definition of a unique objective function. For this purpose, PSO was coupled with fuzzy logic. First, fuzzy membership functions of two objectives were generated in which the mathematical objective functions are treated as constrains (Eq. 8). In other words, each fuzzy membership function represents a fuzzy region of acceptability.

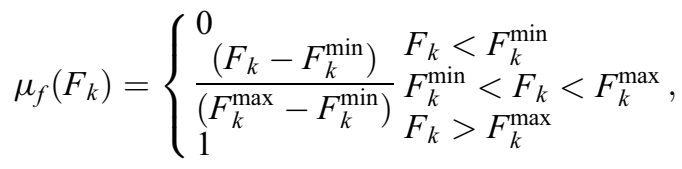

where $\mu_{f}\left(F_{k}\right)$ is fuzzy membership function of $k$, the objective function $(k=1$, for the first and $k=2$, for the second response of each case study), $F_{k}$ is the $k$ th response, $F_{k}^{\min }$ and $F_{k}^{\max }$ are minimum and maximum values for each objective function, respectively. Following this, the new objective function can be defined as a function called zeta:

$$
\zeta_{j}=\min \left\{\mu_{f}\left(F_{1}\right), \mu_{f}\left(F_{2}\right)\right\}_{j},
$$

where $\zeta_{j}$ is satisfaction factor and the subscribe $j=1: 25$ denotes the particle number. For two case studies, $\mu_{f}\left(F_{1}\right)$ was practical (IFT or SC) while $\mu_{f}\left(F_{2}\right)$ was economic (CE or CoMP) fuzzy membership functions, respectively.

The best solution of current iteration (pbest ${ }_{i}$ ) has the maximum value of particles' zeta:

$$
(\text { pbest })_{i} \equiv \max \left\{\zeta_{j}\right\},
$$

In the next iteration, a new swarm containing random particles is generated whose positions and velocities are updated according to equations (1) and (2), respectively. Finally, the multi-criteria solution is gbest:

$$
\text { gbest }=\max \left\{(\text { pbest })_{i}\right\},
$$

where gbest is the best global solution and pbest $t_{i}$ is the best local solution of $i$ th iteration $(i=1: 60)$.

\section{RESULTS}

\subsection{Confirmation of Proposed Methodology in Case Study 1}

Considering multiple criteria, different methodologies were employed to develop an efficient algorithm for modeling and optimization of the process. To evaluate this workflow, two case studies of microemulsion flooding were considered. As shown in Figure 1, the algorithm was commenced with RSM (D-optimal method) by which 50 experiments were designed. Then, the responses have been provided. As mentioned before, the responses were numerically calculated using ANN paradigm whose results are presented and discussed as follows:

\subsubsection{Modeling of Microemulsion Flooding Using ANN}

ANN was used to model the production of triglyceride microemulsion, performing as a numerical simulator to provide the responses of D-optimal design. The neurosimulation process was started with training of a multi-layer back propagation network using training dataset. Error analysis of this phase is presented in Figure 2. Error analysis of MAPE and SMAPE for IFT response were $2833.1 \%$ and $107.8 \%$, respectively (Fig. 2(a), blue column) while they were calculated as less than $2 \%$ for RF response (Fig. 2(b), blue column). ANN was not trained for IFT very well although the results were acceptable for RF.

Comparing the predicted values of IFT with real ones in training dataset, it appears the huge error of MAPE has stemmed from two points. First, we found ANN predicted several negative IFT which are conceptually impossible for such oleic/ aqueous systems. Second, the training precision was the worst for low and ultralow IFT. To improve the accuracy of neurosimulation, the original dataset should be analyzed owing to the fact that ANN is an information-processing methodology and it is strongly dependent on the original data. For this end, the spatial distribution of original responses is plotted in Figure 3 (a) using a 3D plot [62]. It reveals that IFT did not lie in a standard distribution pattern because there is a marked difference between the minimum and maximum values of IFT $(0.0001 \leq$ $\mathrm{IFT} \leq 11.2530$ ). By contrast, RF was expanded over a limited domain. Since IFT was varied over several orders of magnitude it could not be trained very well.

To modify the wide distribution of IFT, some transformations were examined. First, it was replaced with $\ln$ (IFT) to restrict its range. In addition, solubilization ratio $(S)$ using Chun Huh equation and $\ln (S)$ were assigned as new transformations:

$$
\mathrm{IFT}=\frac{c}{S^{2}},
$$

where $c$ is constant (usually 0.3 ). To compare the spatial distribution of IFT original dataset with its transformed forms, the Standard Deviation (SD) as a useful indicator was employed. It evaluates the dispersion of the dataset:

$$
\mathrm{SD}=\left(\frac{1}{n-1} \sum_{i=1}^{n}\left(x_{i}-\mu\right)^{2}\right)^{1 / 2},
$$

where $x_{i}$ is the $i$ th sample of the dataset, $\mu$ denotes the mean of value, and $n$ is the number of samples. 

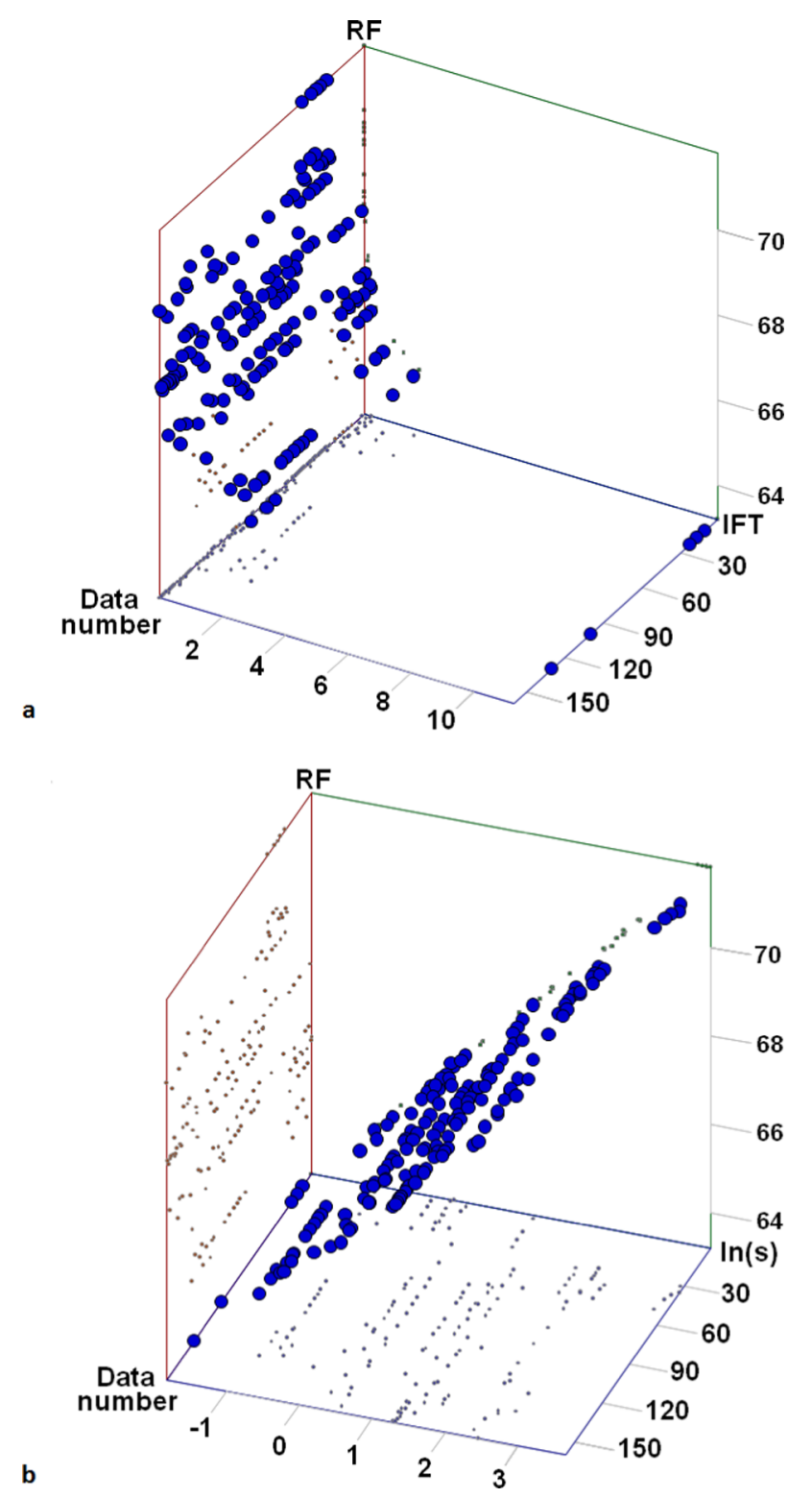

Figure 3

The spatial distribution of outputs in case study 1: (a) IFT and $\mathrm{RF}(\mathrm{b}) \ln (S)$ and RF.

The values of standard deviation for original and transformed datasets of IFTwere as follows: IFT $=1.97, \ln (\mathrm{IFT})=2.39, S=6.77$ and $\ln (S)=1.19$. They implies $\ln (S)$ provided the best distribution among others as the variations of IFT was modified very well $(-1.8<\ln (S)<3.7)$; compared to original IFT $(0.0001 \leq$ IFT $\leq 11.2530$ ). The spatial distribution of $\ln (S)$ is visualized in Figure 3(b) which demonstrates its uniform distribution and narrower range of variations over the search space.

The effects of different transformations on the performance of the trained network are presented in Figure 2. Replacing IFT with $\ln (S)$ improved the quality of training significantly. MAPE and SMAPE were considerably reduced from $2833.1 \%$ to $65.7 \%$ and from $107.8 \%$ to $49.8 \%$, respectively.
It is noteworthy that error analysis based on just one parameter (either MAPE or RMSE) can be misleading [6365]. For example, RMSE of IFT (without any transformation) was 0.1215 , compared to $\ln (S)$ which was 0.4602 . A brief glance confirms that the transformations did not affect serious improvement if only RMSE was considered. However, MAPE and SMAPE of IFT were extremely high compared to $\ln (S)$. That is why the efficiency of training was examined based on three error estimators.

Accordingly, the use of SMAPE beside MAPE is essential because MAPE can be varied between zero and infinity while the upper endpoint of SMAPE (Eq. 6) is restricted to $200 \%$ [66, 67]. In the current case, MAPE of $2833.1 \%$ does not make sense for engineers but they can deal better with SMAPE of $104.8 \%$. Although the application of $\ln (S)$ boosted the performance of ANN training, current values of MAPE (66.7\%) and SMAPE (49.8\%) indicate that accuracy of ANN modeling should be further improved. In the generalization phase, attempts were made to increase ANN accuracy.

The efficiency of the trained network to predict a newly presented unseen data (evaluation dataset) was gradually improved during generalization operation in terms of the training algorithm, number of neurons, and performance goal.

In this step, 10 training algorithms were tested. Figure 4 demonstrates that the most efficient algorithm is Bayesian regularization back propagation by which overfitting can be prevented [41]. MAPE of $\ln (S)$ decreased substantially from $43.6 \%$ to $1.86 \%$ and SMAPE declined from $39.1 \%$ to $1.87 \%$ when Levenberg-Marquardt algorithm (default algorithm in training phase) was replaced with Bayesian regularization. Similar to $\ln (S)$, SMAPE of RF was reduced from $0.74 \%$ to $0.05 \%$.

Following this, the optimal number of neurons was selected. For this end, it was changed from 1 to 15 and the variations of RMSE were followed. Figure 5 shows that the optimum neuron number was 10 since RMSE of $\ln (S)$ and RF were the least. Finally, the performance goal of training was reduced to $1 \times 10^{-5}$ to minimize the prediction errors.

Thanks to the successful transform function of original response (IFT) to $\ln (S)$ and efficient structure of the network optimized during generalization operation, the accuracy of the ANN predictions improved significantly as indicated in Table 4. The overall errors of responses have been almost reduced less than $1 \%$, demonstrating the efficiency of ANN to be successfully used for the accurate prediction of unknown data (has not been introduced to the network). Graphically, the crossplots of ANN estimation and original data in training and generalization phases are shown in Figure 6.

Eventually, the trained network with optimum structure was ready to be used as the surrogate model to produce 50 pairs of responses required for RSM. It is called operation phase in which new inputs are introduced to the network and 

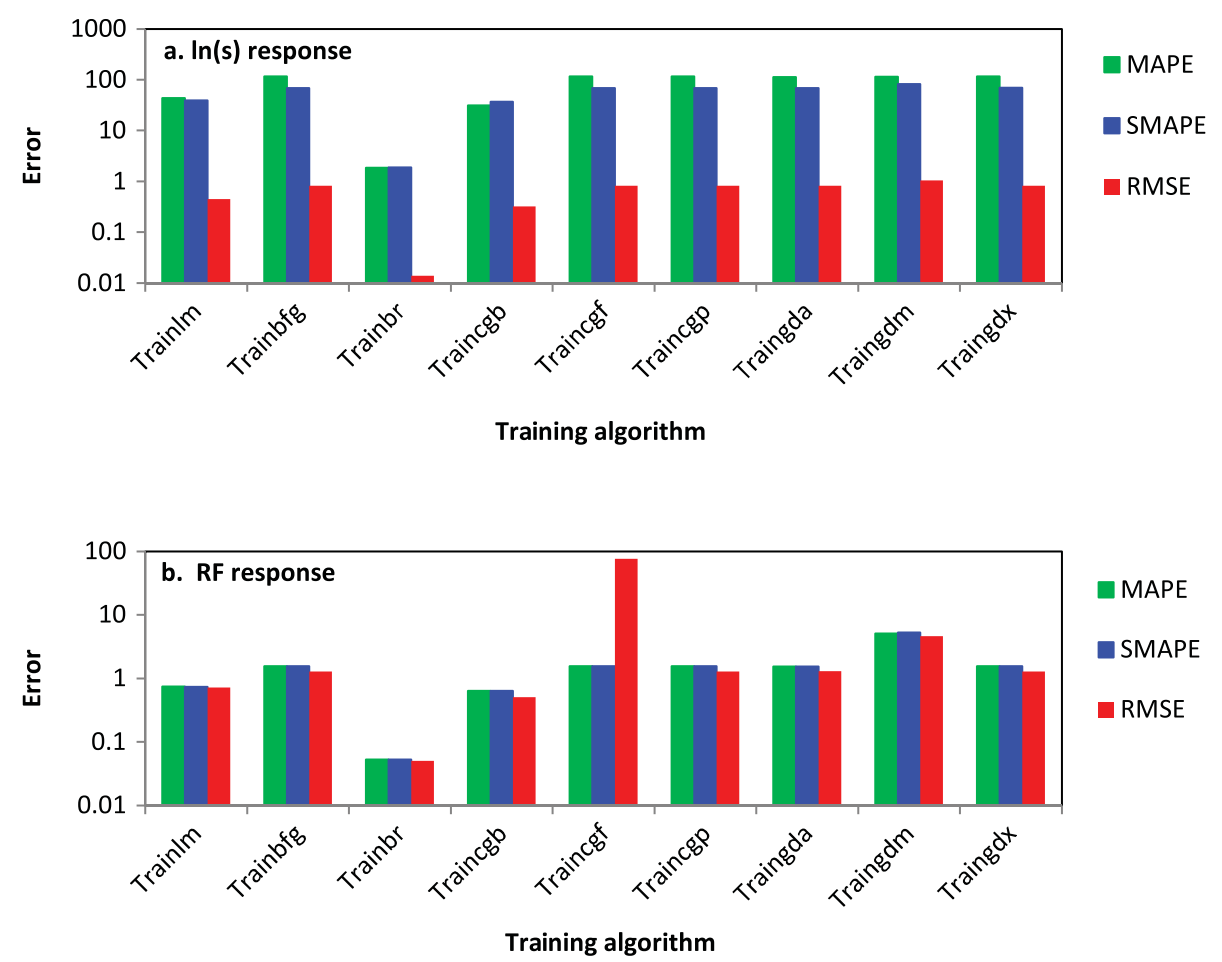

Figure 4

The effect of training algorithms on the ANN prediction in generalization phase, (a) $\ln (S)$ and (b) recovery factor.

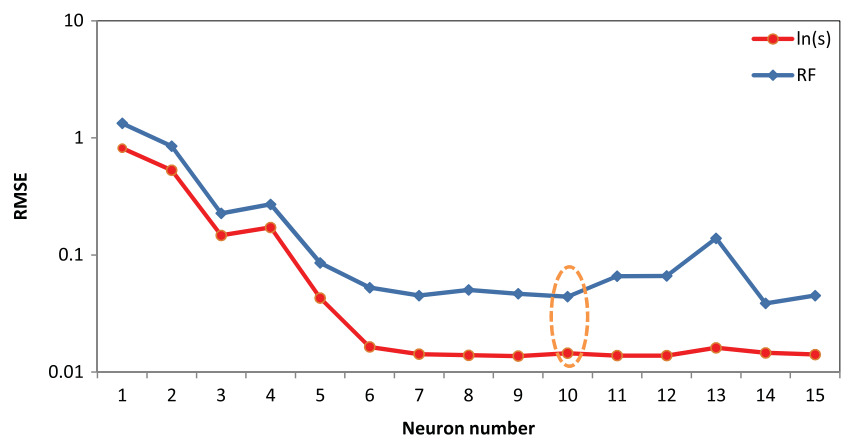

Figure 5

The effect of neuron number in the hidden layer on the accuracy of ANN predictions.

ANN can estimate output(s). Here, it was utilized to calculate the required responses of RSM. 50 runs of experimental design as testing dataset were fed to ANN and the corresponding responses were provided.

\subsubsection{Generation of Objective Functions Using RSM (D- Optimal Pattern)}

The provided responses from the previous stage were imported into software to fit quadratic models using RSM, developing objective functions. Statistical analysis of proposed mathematical models was tabulated in Table 5. Based on the results of ANOVA, the $F$ Values for $\ln (S)$ and CE models were 139.00 and 1949.15, respectively. Moreover, the
TABLE 4

The performance of optimum ANN structure in generalization phase.

\begin{tabular}{l|l|l}
\hline Output & Estimator & Error \\
\hline \multirow{4}{*}{$\ln (s)$} & MAPE & $1.2493 \%$ \\
\cline { 2 - 3 } & SMAPE & $1.3437 \%$ \\
\cline { 2 - 3 } & RMSE & 0.0099 \\
\hline \multirow{3}{*}{ RF } & MAPE & $0.0373 \%$ \\
\cline { 2 - 3 } & SMAPE & $0.0373 \%$ \\
\cline { 2 - 3 } & RMSE & $0.0369 \%$ \\
\hline
\end{tabular}

values of Prob $>F$ were less than 0.0001 which indicates that both quadratic models were significant in $99.9 \%$ confidence interval. Other parameters of this table confirmed the performance of fitted equations; for instance, $R^{2}$ and $R_{a d j}^{2}$ of $\ln (S)$ were 0.9823 and 0.9753 while these control factors were calculated as 0.9987 and 0.9982 for CE. They demonstrated that equations fitted numerical data very well. The quadratic models (Appendix B) were extracted as objective functions of optimization process.

\subsubsection{Multi-Objective Optimization}

Having fitted quadratic equations, multi-attribute optimization was initiated. In each iteration of PSO, there was a swarm of 25 particles and optimization algorithm was continued to 60 iterations. 

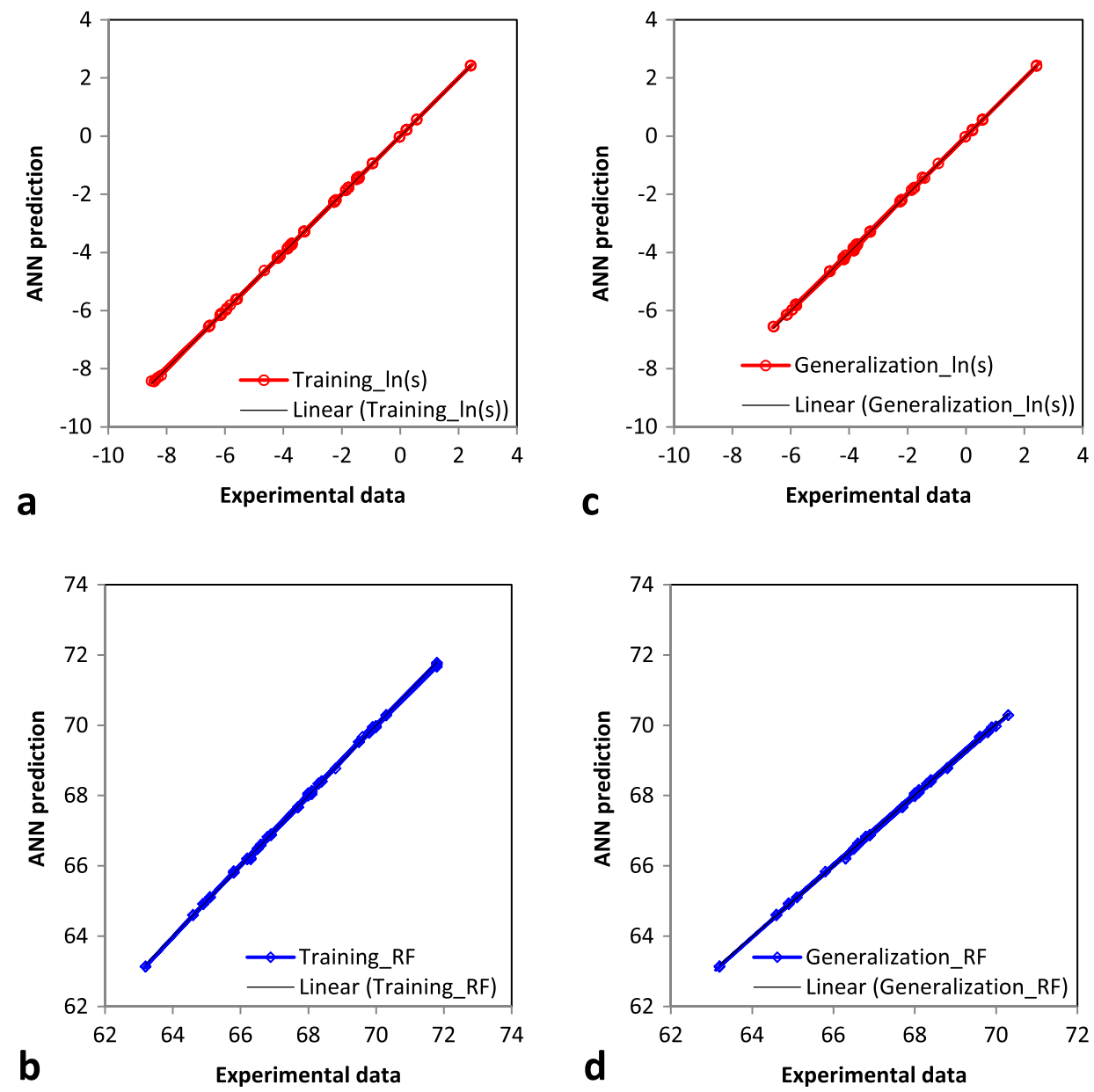

Figure 6

The crossplots of ANN predictions versus actual data for training phase of (a) $\ln (S)$ and (b) recovery factor, generalization phase of (c) $\ln (S)$, and (d) recovery factor.

TABLE 5

The results of ANOVA for two case studies.

\begin{tabular}{|c|c|c|c|c|}
\hline \multirow{2}{*}{ Statistical results } & \multicolumn{2}{|c|}{ Case study 1} & \multicolumn{2}{|c|}{ Case study 2} \\
\hline & 1st Response & 2nd Response & 1st Response & 2nd Response \\
\hline Model $F$ value & 139.00 & 1949.15 & 46.41 & 39.08 \\
\hline Model prob $>F$ & $<0.0001$ & $<0.0001$ & $<0.0001$ & $<0.0001$ \\
\hline$R$-squared $\left(R^{2}\right)$ & 0.9823 & 0.9987 & 0.9659 & 0.9598 \\
\hline Adjusted $R$-squared $\left(R_{a d j}^{2}\right)$ & 0.9753 & 0.9982 & 0.9451 & 0.9353 \\
\hline Predicted $R$-squared $\left(R_{\text {pred }}^{2}\right)$ & 0.9643 & 0.9974 & 0.8774 & 0.8719 \\
\hline $\mathrm{CV} \%$ & 8.36 & 1.14 & 9.54 & 6.92 \\
\hline Adequate precision & 44.147 & 132.698 & 23.413 & 22.424 \\
\hline
\end{tabular}

In each iteration, position and velocity of every particle were randomly determined. Then, corresponding responses were calculated using objective functions (Appendix B). Following this, zeta function (Eq. 9) was used to find satisfaction factor of each particle, facilitating multi- objective optimization. The maximum value of $\zeta$ was assigned as pbest of curriculum iteration. Proceeding with the optimization process, $\zeta$ was increased. The variations of two original responses (outputs) during the progress of PSOFL methodology are demonstrated in Figure 7 which 
indicates that the IFT decreased while the RF increased simultaneously until they reached their optimal values. Optimum arrangement of control variables by which gbest was achieved, are tabulated in Table 6. The algorithm proposed the optimum formulation of microemulsion as follows: surfactant concentration of $1.04 \mathrm{wt} \%$, salinity of $4.2 \mathrm{wt} \%$, co-surfactant concentration of $2.93 \mathrm{wt} \%$ and water content of $94 \mathrm{wt} \%$. Performing this formulation, the algorithm was predicted ultra-low IFT of $4.01 \times 10^{-4} \mathrm{mN} /$ $\mathrm{m}$ and chemical efficiency up to $13.50 \%$. The trend of improvement for original responses is ploted in Figure 7.

To confirm the results achieved by PSO-FL methodology, RSM as a multi-purpose optimization technique was employed. The results are presented in Table 6. It shows that the optimum formulation of microemulsion had ultralow IFT of $2.81 \times 10^{-4} \mathrm{mN} / \mathrm{m}$ and chemical efficiency of $13.18 \%$. The results of PSO-FL were in consistent with those of RSM. Compared two methodologies, one can easily prove the efficacy of PSO-FL. Moreover, the results of PSOFL were compared to single-objective optimization of each individual response. It indicates the trade-off between conflicting objectives could not be extracted when singleobjective algorithms were used which may mislead the engineers in such multi-attribute problems.

\subsection{Case Study 2}

\subsubsection{Development of Objective Functions Using RSM (CCD Plan)}

According to CCD approach, 30 experiments were designed. Insofar as the required responses were exactly available in the literature, they were gathered and directly fed into the RSM. In other words, the implementation of neuro-simulation step in the workflow (Fig. 1) did not necessitate for this case study. Anyway, RSM employed different control statistical parameters to develop precise quadratic models fitted to experimental data. Based on the results of ANOVA, the $F$ Value of responses for solubilization capacity and cost of chemicals were calculated as 46.41 and 39.08 while Prob $>F$ were less than 0.0001 for both responses. These values indicate the developed models were statistically significant in $99.9 \%$ confidence level $(p$-value $<0.001) . R^{2}, R_{a d j}^{2}$ were calculated as 0.9659 and 0.9451 for solubilization capacity response. On the other hand, they were assessed at 0.9598 and 0.9353 for the second output (the cost of microemulsion production). Other statistical parameters are presented in Table 5. The results of ANOVA table pointed to favorable fits of quadratic equations (Appendix C) to experimental data.

\subsubsection{Multi-Objective Optimization}

The fitted quadratic equations were used as objective functions in the PSO-FL algorithm whereby the trade-off between technical and economic objectives was considered.

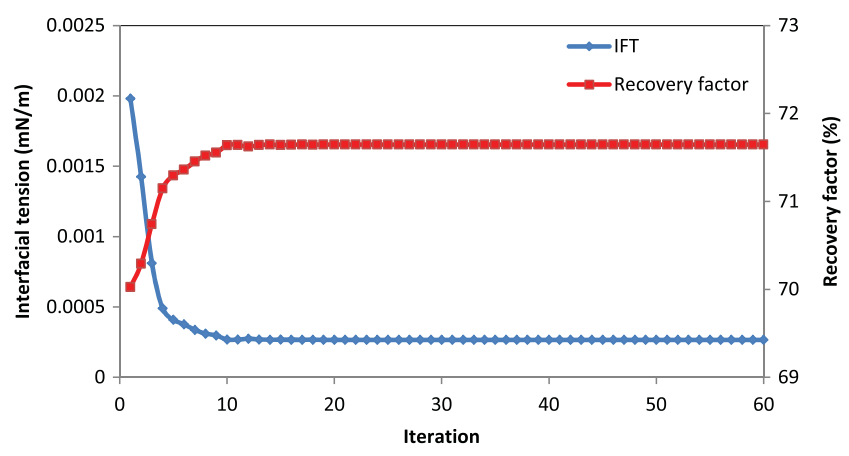

Figure 7

The improvement of two original responses toward their optimum values during PSO-FL methodology in case study 1.

Table 7 shows the optimal formulation of microemulsion. When aqueous phase $(60 \mathrm{v} \%)$ consisting of $3.48 \mathrm{wt} \%$ surfactant and $4.2 \mathrm{wt} \% \mathrm{NaCl}$ was mixed with oleic phase ( $40 \mathrm{v} \%$ ) comprising $86.73 \mathrm{v} \%$ biodiesel and $13.27 \mathrm{v} \%$ cosolvent, the solubilization capacity reached up to $8.69 \%$ and the cost of microemulsion formulation was simultaneously reduced to $9.93 \$ / b b l$.

The prominent role of PSO-FL methodology to consider trade-off between technical and economic matters of a process (here microemulsion formulation) was revealed when the best estimation of PSO-FL workflow was compared to PSO algorithm as a singleobjective paradigm.

When the first response (SC) was solely considered, the optimal concentrations of surfactant and co-solvent were $5.62 \mathrm{wt} \%$ and $15.00 \mathrm{v} \%$, respectively. Although the solubilization capacity increased from $8.69 \%$ (PSO-FL: SC\&CoMP) to $11.30 \%$ (PSO: SC), $22.7 \%$ rise in the cost of formulation was observed (from $9.93 \$ / b b l$ to $12.18 \$ /$ bbl). On the other hand, the cheapest formulation was achieved when the single-objective PSO algorithm was run just based on the cost of chemicals. In this case, the optimum concentrations of surfactant and co-solvent were predicted as $1.78 \mathrm{wt} \%$ and $5 \mathrm{v} \%$, respectively. Although the formulation cost was substantially reduced by $33.6 \%$ (from $9.93 \$ /$ bbl to $6.59 \$ / b b l$ ), poor quality of formulation was observed because solubilization capacity decreased drastically from $8.69 \%$ to $3.16 \%$. A remarkable difference between singleand multi-objective optimization algorithms was explicitly indicated. Therefore, competing objectives necessitate the application of multi-attribute methodologies unless trade-off decisions cannot be made.

In the background section, several issues were discussed regarding the application of microemulsion for CEOR applications. The last two ones were salinity and formation damage. There was a wide range of salinity in the experimental evaluations of microemulsions in both case studies (Tabs. 2 and 3) which include many compositions of 
TABLE 6

The optimum microemulsion slug achieved by different methods in case study 1 .

\begin{tabular}{l|l|l|l|l|l|l}
\hline \multirow{2}{*}{ Methodology } & \multicolumn{3}{|c|}{ Control variables } & \multicolumn{2}{c}{ Responses } \\
\cline { 2 - 7 } & $C_{A P G}(\mathrm{wt} \%)$ & $S(\mathrm{wt} \%)$ & $C_{G M}(\mathrm{wt} \%)$ & $W(\mathrm{wt} \%)$ & IFT $(\mathrm{mN} / \mathrm{m})$ & $4.01 \times 10^{-4}$ \\
\hline PSO-FL: IFT\&CE & 1.04 & 4.2 & 2.93 & 94 & 13.50 \\
\hline RSM: IFT\&CE & 1.06 & 4.2 & 3.12 & 94 & $4.01 \times 10^{-4}$ & 13.18 \\
\hline PSO: IFT & 1.13 & 4.2 & 3.13 & 94 & $3.82 \times 10^{-4}$ & 13.09 \\
\hline PSO: CE & 0.88 & 4.2 & 1.38 & 94 & $1.97 \times 10^{-2}$ & 16.40 \\
\hline
\end{tabular}

TABLE 7

The optimum formulations of microemulsion in case study 2 .

\begin{tabular}{l|l|l|l|l|l|l}
\hline \multirow{2}{*}{ Methodology } & \multicolumn{3}{|c|}{ Control variables } & \multicolumn{3}{c}{ Responses } \\
\cline { 2 - 8 } & $C_{P S}(\mathrm{wt} \%)$ & $S(\mathrm{wt} \%)$ & $C_{E t h}(\mathrm{v} \%)$ & $\alpha(\mathrm{v} \%)$ & SC $(\%)$ & CoMP $(\$ / \mathrm{bbl})$ \\
\hline PSO-FL: SC\&CoMP & 3.48 & 4.2 & 13.27 & 40.00 & 8.69 & 9.93 \\
\hline PSO:SC & 5.62 & 4.2 & 15.00 & 40.00 & 11.30 & 12.18 \\
\hline PSO:CoMP & 1.78 & 4.2 & 5.00 & 30.71 & 3.16 & 6.59 \\
\hline
\end{tabular}

TABLE 8

The comparison of average particle size in microemulsion and throat diameter in different porous media.

\begin{tabular}{l|l|l|l}
\hline Sample & Porosity (\%) & Average particle/throat diameter (nm) & Reference \\
\hline Microemulsion (Case study 2) & - & 56 & {$[28]$} \\
\hline Tight carbonate, Sichuan Basin, China (Type I) & 1.3 & $126-320$ & {$[69]$} \\
\hline Tight carbonate, Sichuan Basin, China (Type II) & $0.8-1.7$ & $20-126$ & $<20$ \\
\hline Tight carbonate, Sichuan Basin, China (Type III) & $<0.8$ & $>253$ & {$[69]$} \\
\hline Middle Eastern carbonate & 47.0 & $>200$ & {$[69]$} \\
\hline Tight sandstone, Ordos Basin, China & $7.0-13.1$ & $28 \times 10^{3}$ & {$[70]$} \\
\hline Berea sandstone & 23.0 & $26 \times 10^{3}$ to $44 \times 10^{3}$ & {$[71]$} \\
\hline Middle Eastern limestone & $16.0-23.6$ & $20 \times 10^{3}$ & {$[72]$} \\
\hline Vuggy carbonate, Bohai Basin, China & 6.9 & {$[73]$} \\
\hline
\end{tabular}

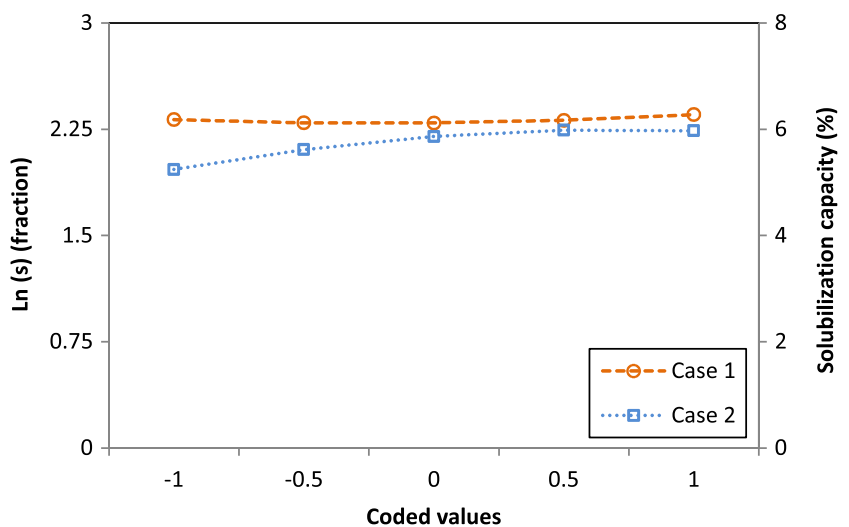

Figure 8

Sensitivity analysis of the effect of salinity on the technical responses in both case studies. sea water and even formation water. The perturbation plot of salinity in these domains is presented in Figure 8 in which the effect of salinity factor on technical responses is examined while other factors were set to their zero (middle) levels in this assessment. It indicates the salinity was not a deterministic factor because the variations of salinity did not significantly influence on the responses in both cases owing to the fact that nonionic surfactants (APG and Polysorbate 80) were used in the microemulsion mixture which is more compatible than ionic surfactants $[28,56]$. As a result, such formulations demonstrate high potential for CEOR operations in unconventional reservoirs; not only for unlimited stability at high temperature but also for high tolerance against high salinity. 
Theoretically, the diameter of microemulsions is less than $100 \mathrm{~nm}$. Generally, the exact size of particles in any dispersion is determined in terms of various parameters, such as the type and concentration of chemicals, thermodynamic conditions of the system, and the source of energy for mixing operation [68]. The $Z$-average diameter of the newly developed formulation was approximately $56 \mathrm{~nm}$ [28]. Table 8 compares it with throat size of different reservoirs. The average diameter of particles was almost smaller than throats in different porous media even some types of tight oil formations. Hence, such colloidal dispersions can be potential candidates for diverse range of reservoirs without any concern regarding the formation damage.

\section{CONCLUSION}

Better design of microemulsion formulation for CEOR purposes is dependent on the optimization of its formulation in the presence of multiple criteria. In this article, a hybrid algorithm was proposed for modeling and multi-criteria optimization of microemulsion formulation in two different case studies. It effectively combined the abilities of response surface methodology as well as artificial neural networks to model the process and then particle swarm optimization and fuzzy logic were coupled to optimize it. To confirm the effectiveness of this algorithm, it was applied on the triglyceride microemulsion in the first case study. Thereafter, it was used for a newly developed microemulsion for hightemperature carbonate reservoirs. Based on the results of these case studies, the following conclusions can be drawn: - algorithms that can consider simultaneously two or more competing objectives are of great interest in the optimization of microemulsion formulation and CEOR processes in general because they regard the problem from different points of view. This article demonstrates that trade-off decisions can be made only when methodologies supporting multiple perspectives are used rather than uniobjective algorithms;

- different techniques were employed in the structure of the hybrid algorithm for the multi-objective optimization of microemulsion formulation in terms of technical and economic aspects. The workflow consisted of two main phases: modeling and optimization. To address the challenges of finding accurate objective functions as the outcome of modeling stage, different approaches were used: appropriate selection of RSM design, modification of the spatial distribution of responses, and optimization of ANN structure. Thus, the overall symmetric prediction error was reduced less than $2 \%$. Furthermore, the results of analysis of variance in RSM indicated that developed quadratic equations as objective functions were fitted very well;
- the coupling of particle swarm optimization and fuzzy logic were found to be a powerful multi-attribute optimization method by which optimal microemulsion formulation was successfully achieved based on conflicting practical and financial objectives;

- the optimization results of microemulsion flooding were confined to lab scale in both case studies and cannot be extended to field scale as the available data had been gathered from experimental works due to the lack of field data. It does not reflected the limitation of proposed workflow for optimization of case studies in field-scale. The introduced methodology can be successfully applied for modeling and multi-purpose optimization of any CEOR process in both lab and field scales if relevant database is collected;

- the microemulsion flooding demonstrates high potential to be used as an effective CEOR approach in different reservoirs.

\section{ACKNOWLEDGMENTS}

The authors would like to thank Dr. Z. Jeirani for provision of experimental data in case study 1 . In addition, the authors are grateful to IOR Research Institute for the financial support. The authors are also thankful to Stat-Ease, Minneapolis for the provision of the Design Expert package.

\section{APPENDIX A}

The data of the first database is available through the reference [57]. The original data of the second case study is presented in Table A1.

TABLE A1

Data of case study 2

\begin{tabular}{l|l|l|l|l|l}
\hline Data & $C_{P S}(\mathrm{wt} \%)$ & $S(\mathrm{wt} \%)$ & $C_{E t h}(\mathrm{v} \%)$ & $\alpha(\mathrm{v} \%)$ & $S C(\%)$ \\
\hline 1 & 0.25 & 7.5 & 15 & 40 & 9.375 \\
\hline 2 & 0.25 & 7.5 & 15 & 20 & 5.156 \\
\hline 3 & 0.50 & 5.0 & 10 & 30 & 5.714 \\
\hline 4 & 0.25 & 2.5 & 5 & 20 & 3.281 \\
\hline 5 & 0.50 & 5.0 & 10 & 30 & 6.071 \\
\hline 6 & 0.25 & 2.5 & 15 & 20 & 6.094 \\
\hline 7 & 0.50 & 5.0 & 0 & 30 & 2.500 \\
\hline 8 & 0.25 & 7.5 & 5 & 40 & 4.167 \\
\hline 9 & 0.75 & 2.5 & 15 & 40 & 10.833 \\
\hline 10 & 0.75 & 7.5 & 5 & 20 & 8.008 \\
\hline 11 & 0.50 & 5.0 & 10 & 10 & 5.417 \\
\hline
\end{tabular}


TABLEA1. (continued).

\begin{tabular}{|c|c|c|c|c|c|}
\hline Data & $C_{P S}(\mathrm{wt} \%)$ & $S(\mathrm{wt} \%)$ & $C_{E t h}(\mathrm{v} \%)$ & $\alpha(\mathrm{v} \%)$ & $S C(\%)$ \\
\hline 12 & 0.75 & 2.5 & 5 & 40 & 5.208 \\
\hline 13 & 0.50 & 0.0 & 10 & 30 & 4.286 \\
\hline 14 & 0.50 & 5.0 & 10 & 30 & 5.714 \\
\hline 15 & 0.50 & 5.0 & 10 & 30 & 5.893 \\
\hline 16 & 0.75 & 7.5 & 5 & 40 & 6.250 \\
\hline 17 & 0.50 & 10.0 & 10 & 30 & 5.357 \\
\hline 18 & 0.00 & 5.0 & 10 & 30 & 4.500 \\
\hline 19 & 0.75 & 7.5 & 15 & 40 & 10.833 \\
\hline 20 & 0.75 & 2.5 & 15 & 20 & 7.813 \\
\hline 21 & 0.50 & 5.0 & 20 & 30 & 10.714 \\
\hline 22 & 0.75 & 2.5 & 5 & 20 & 5.938 \\
\hline 23 & 0.50 & 5.0 & 10 & 30 & 6.071 \\
\hline 24 & 0.25 & 2.5 & 15 & 40 & 8.958 \\
\hline 25 & 0.25 & 7.5 & 5 & 20 & 3.125 \\
\hline 26 & 0.50 & 5.0 & 10 & 50 & 8.750 \\
\hline 27 & 0.25 & 2.5 & 5 & 40 & 3.125 \\
\hline 28 & 0.50 & 5.0 & 10 & 30 & 5.714 \\
\hline 29 & 0.75 & 7.5 & 15 & 20 & 10.938 \\
\hline 30 & 1.00 & 5.0 & 10 & 30 & 12.857 \\
\hline
\end{tabular}

\section{APPENDIX B}

Quadratic equations developed as objective functions of case study 1 :

$$
\begin{aligned}
& \ln (S)=-17.17441+7.70181 \times C_{A P G} \\
& +0.11965 \times S-5.25252 \times C_{G M} \\
& +0.43211 \times W+0.013832 \times C_{A P G} \times S \\
& +0.21979 \times C_{A P G} \times C_{G M}+0.031156 \\
& \times C_{A P G} \times W+0.048413 \times S \times C_{G M} \\
& -3.45166 \times 10^{-3} \times S \times W+0.060503 \\
& \times C_{G M} \times W-5.03474 \times C_{A P G}^{2} \\
& +5.47495 \times 10^{-3} \times S^{2}+0.024399 \\
& \times C_{G M}^{2}-3.1647 \times 10^{-3} \times W^{2} . \\
& C E=+321.27378+13.73704 \times C_{A P G} \\
& +0.11330 \times S+9.93377 \times C_{G M}-8.07206 \\
& \times W+0.014315 \times C_{A P G} \times S+0.31434 \\
& \times C_{A P G} \times C_{G M}-0.14690 \times C_{A P G} \times W \\
& +0.010427 \times S \times C_{G M}-8.29430 \times 10^{-3} \\
& \times S \times W-0.13499 \times C_{G M} \times W \\
& -1.06852 \times C_{A P G}^{2}-6.10686 \times 10^{-3} \times S^{2} \\
& +0.15852 \times C_{G M}^{2}+0.051804 \times W^{2},
\end{aligned}
$$

where $C_{A P G}, S, C_{G M}$ and $W$ are representative of four control variables in the first case study (Tab. 2). $\ln (S)$ and $C E$ are the corresponding responses.

\section{APPENDIX C}

Second-order models used in PSO-FL methodology of case study 2 :

$$
\begin{aligned}
S C & =+4.36554-2.05650 \times C_{P S}+0.26300 \\
& \times S-0.19228 \times C_{E t h}-0.17319 \times \alpha \\
& +0.58720 \times C_{P S} \times S-0.18855 \times C_{P S} \times \alpha \\
& +0.014500 \times C_{E t h} \times \alpha+11.31933 \times C_{P S}^{2} \\
& -0.041087 \times S^{2}+7.58333 \times 10^{-3} \times C_{E t h}^{2} \\
& +3.08708 \times 10^{-3} \times \alpha^{2}
\end{aligned}
$$

$$
\begin{aligned}
\text { CoMP } & =+8.95501-0.88630 \times C_{P S}+0.10864 \\
& \times S-0.037605 \times C_{E t h}-0.14921 \times \alpha \\
& +0.81797 \times C_{P S} \times S-0.29422 \times A \\
& \times \alpha+9.17982 \times 10^{-3} \times C_{E t h} \times \alpha \\
& +12.41793 \times C_{P S}^{2}-0.033243 \times S^{2} \\
& +5.32396 \times 10^{-3} \times C_{E t h}^{2}+1.94735 \\
& \times 10^{-3} \times \alpha^{2},
\end{aligned}
$$

where $C_{P S}, S, C_{E t h}$ and $\alpha$ are representative of four factors in the second case study (Tab. 3). SC and CoMP are the responses of this process.

\section{REFERENCES}

1 Alvarado V., Manrique E. (2010) Enhanced oil recovery: An update review, Energies 3, 1529-1575.

2 Ayirala S.C., Yousef A.A. (2015) A state-of-the-art review to develop injection-water-chemistry requirement guidelines for IOR/EOR projects, SPE Prod. Oper. 30, 26-42.

3 Chen F., Jiang H., Bai X., Zheng W. (2013) Evaluation the performance of sodium metaborate as a novel alkali in alkali/ surfactant/polymer flooding, J. Ind. Eng. Chem. 19, 450-457.

4 Iglauer S., Paluszny A., Blunt M.J. (2013) Simultaneous oil recovery and residual gas storage: A pore-level analysis using in situ X-ray micro-tomography, Fuel 103, 905-914.

5 Jang H.Y., Zhang K., Chon B.H., Choi H.J. (2015) Enhanced oil recovery performance and viscosity characteristics of polysaccharide xanthan gum solution, J. Ind. Eng. Chem. 21, $741-745$

6 Santanna V.C., Curbelo F.D.S., Castro Dantas T.N., Dantas Neto A.A., Albuquerque H.S., Garnica A.I.C. (2009) Microemulsion flooding for enhanced oil recovery, J. Pet. Sci. Eng. 66, $117-120$.

7 Jeirani Z., Mohamed Jan B., Si Ali B., Noor I.M., See C.H., Saphanuchart W. (2013) Correlations between interfacial tension and cumulative tertiary oil recovery in a triglyceride microemulsion flooding, J. Ind. Eng. Chem. 19, 1310-1314.

8 Bera A., Kumar T., Ojha K., Mandal A. (2014) Screening of microemulsion properties for application in enhanced oil recovery, Fuel 121, 198-207.

9 Fathi Z., Ramirez W.F. (1984) Optimal injection policies for enhanced oil recovery: part 2-surfactant flooding, Soc. Petrol. Eng. J. 24, 333-341. 
10 Zerpa L.E., Queipo N.V., Pintos S., Salager J.L. (2005) An optimization methodology of alkaline-surfactant-polymer flooding processes using field scale numerical simulation and multiple surrogates, J. Pet. Sci. Eng. 47, 197-208.

11 Carrero E., Queipo N.V., Pintos S., Zerpa L.E. (2007) Global sensitivity analysis of Alkali-Surfactant-Polymer enhanced oil recovery processes, J. Pet. Sci. Eng. 58, 30-42.

12 Poettmann, F.H., Hause, W.R. (1978) Micellar-Polymer Screening Criteria And Design, SPE Paper 7068, in: Presented at SPE Symposium on Improved Methods of Oil Recovery, 16-17 April, Tulsa, Oklahoma.

13 Wu W., Vaskas A., Delshad M., Pope G.A., Sepehrnoori K. (1996) Design and optimization of low-cost chemical flooding, SPE Paper 35355, in: Presented at SPE/DOE Improved Oil Recovery Symposium, Tulsa, Oklahoma.

14 Anderson G.A., Delshad M., King C.B., Mohammadi H., Pope G.A. (2006) Optimization of chemical flooding in a mixed-wet dolomite reservoir, SPE Paper 100082, in: Presented at SPE/ DOE Symposium on Improved Oil Recovery, Tulsa, Oklahoma.

15 Prasanphanich J., Kalaei M.H., Delshad M., Sepehrnoori K. (2012) Chemical flooding optimisation using the experimental design approach and response surface methodology, Int. J. Oil Gas Coal. Tech. 5, 368-384.

16 Douarche F., Da Veiga S., Feraille M., Enchéry G., Touzani S., Barsalou R. (2014) Sensitivity analysis and optimization of surfactant-polymer flooding under uncertainties, Oil Gas Sci. Technol. - Rev. IFP 69, 603-617.

17 AlSofi A.M., Blunt M.J. (2014) Polymer flooding design and optimization under economic uncertainty, J. Pet. Sci. Eng. 124, 46-59.

18 Ebbesen S., Elbert P., Guzzella L. (2013) Engine downsizing and electric hybridization under consideration of cost and drivability, Oil Gas Sci. Technol. - Rev. IFP 68, 109-116.

19 Ahmadi M.H., Ahmadi M.A., Feidt M. (2016) Performance optimization of a solar-driven multi-step irreversible brayton cycle based on a multi-objective genetic algorithm, Oil Gas Sci. Technol. - Rev. IFP 71, 1-14.

20 Zhang H., Dong M., Zhao S. (2010) Which one is more important in chemical flooding for enhanced court heavy oil recovery, lowering interfacial tension or reducing water mobility? Energy \& Fuels 24, 1829-1836.

21 Liu R., Pu W., Wang L., Chen Q., Li Z., Li Y., Li B. (2015) Solution properties and phase behavior of a combination flooding system consisting of hydrophobically amphoteric polyacrylamide, alkyl polyglycoside and n-alcohol at high salinities, RSC Adv. 5, 69980-69989.

22 Iglauer S., Wu Y., Shuler P., Tang Y., Goddard Iii W.A. (2010) New surfactant classes for enhanced oil recovery and their tertiary oil recovery potential, J. Pet. Sci. Eng. 71, 23-29.

23 Guo Y.j., Liu J.x., Zhang X.m., Feng R.s., Li H.b., Zhang J., Lv X., Luo P.y. (2012) Solution property investigation of combination flooding systems consisting of gemini-non-ionic mixed surfactant and hydrophobically associating polyacrylamide for enhanced oil recovery, Energy \& Fuels 26, 21162123.

24 Marcus J., Wolfrum S., Touraud D., Kunz W. (2015) Influence of high intensity sweeteners and sugar alcohols on a beverage microemulsion, J. Colloid Interf. Sci. 460, 105-112.

25 Bardhan S., Kundu K., Saha S.K., Paul B.K. (2013) Physicochemical studies of mixed surfactant microemulsions with isopropyl myristate as oil, J. Colloid Interf. Sci. 402, 180189.

26 McClements D.J. (2012) Nanoemulsions versus microemulsions: terminology, differences, and similarities, Soft Matter 8 , $1719-1729$
27 Mason T.G., Wilking J.N., Meleson K., Chang C.B., Graves S. M. (2006) Nanoemulsions: formation, structure, and physical properties, J. Phys. Condens. Matter 18, 635-666.

28 Karambeigi M.S., Nasiri M., Haghighi Asl A., Emadi M.A. (2016) Enhanced oil recovery in high temperature carbonates using microemulsions formulated with a new hydrophobic component, J. Ind. Eng. Chem. 39, 136-148.

29 Esfandian H., Samadi-Maybodi A., Parvini M., Khoshandam B. (2016) Development of a novel method for the removal of diazinon pesticide from aqueous solution and modeling by artificial neural networks (ANN), J. Ind. Eng. Chem. 35, 295-308.

30 Bezerra M.A., Santelli R.E., Oliveira E.P., Villar L.S., Escaleira L.A. (2008) Response surface methodology (RSM) as a tool for optimization in analytical chemistry, Talanta 76, 965-977.

31 Rahimi K., Towfighi J., Sedighi M., Masoumi S., Kooshki Z. (2016) The effects of $\mathrm{SiO} 2 / \mathrm{Al} 2 \mathrm{O} 3$ and $\mathrm{H} 2 \mathrm{O} / \mathrm{Al} 2 \mathrm{O} 3$ molar ratios on SAPO-34 catalysts in methanol to olefins (MTO) process using experimental design, J. Ind. Eng. Chem. 35, 123-131.

32 Jeirani Z., Mohamed Jan B., Si Ali B., Mohd Noor I., See C.H., Saphanuchart W. (2013) Prediction of water and oil percolation thresholds of a microemulsion by modeling of dynamic viscosity using response surface methodology, J. Ind. Eng. Chem. 19, 554-560.

33 Khuri A.I., Mukhopadhyay S. (2010) Response surface methodology, Wiley Interdiscip. Rev. Comput. Stat. 2, 128-149.

34 Chapoy A., Mohammadi A.H., Richon D. (2007) Predicting the hydrate stability zones of natural gases using artificial neural networks, Oil Gas Sci. Technol - Rev. IFP 62, 701-706.

35 Guilherme I.R., Marana A.N., Papa J.P., Chiachia G., Afonso L.C.S., Miura K., Ferreira M.V.D., Torres F. (2011) Petroleum well drilling monitoring through cutting image analysis and artificial intelligence techniques, Eng. Appl. Artif. Intell. 24, 201-207.

36 Li X., Chan C.W. (2010) Application of an enhanced decision tree learning approach for prediction of petroleum production, Eng. Appl. Artif. Intell. 23, 102-109.

37 Mohaghegh S. (2000) Virtual-intelligence applications in petroleum engineering: Part I - Artificial neural networks, $J$. Petrol. Technol. 52, 64-73.

38 Al-Dousari M.M., Garrouch A.A. (2013) An artificial neural network model for predicting the recovery performance of surfactant polymer floods, J. Pet. Sci. Eng. 109, 51-62.

39 Fathinasab M., Ayatollahi S., Hemmati-Sarapardeh A. (2015) A rigorous approach to predict nitrogen-crude oil minimum miscibility pressure of pure and nitrogen mixtures, Fluid Phase Equilib. 399, 30-39.

40 Salahshoor K., Zakeri S., Haghighat Sefat M. (2013) Stabilization of gas-lift oil wells by a nonlinear model predictive control scheme based on adaptive neural network models, Eng. Appl. Artif. Intell. 26, 1902-1910.

41 Karambeigi M.S., Zabihi R., Hekmat Z. (2011) Neurosimulation modeling of chemical flooding, J. Pet. Sci. Eng. 78, 208-219.

42 Kennedy J., Eberhart R. (1995) Particle swarm optimization, in: IEEE International Conference on Neural Networks, pp. 1942-1948.

43 Nezamabadi-Pour H. (2015) A quantum-inspired gravitational search algorithm for binary encoded optimization problems, Eng. Appl. Artif. Intell. 40, 62-75.

44 Forouzanfar M., Forghani N., Teshnehlab M. (2010) Parameter optimization of improved fuzzy c-means clustering algorithm for brain MR image segmentation, Eng. Appl. Artif. Intell. 23, $160-168$. 
45 Reche López P., Jurado F., Ruiz Reyes N., García Galán S., Gómez M. (2008) Particle swarm optimization for biomassfuelled systems with technical constraints, Eng. Appl. Artif. Intell. 21, 1389-1396.

46 Neyestani M., Farsangi M.M., Nezamabadi-Pour H. (2010) A modified particle swarm optimization for economic dispatch with non-smooth cost functions, Eng. Appl. Artif. Intell. 23, 1121-1126.

47 Zadeh L.A. (1965) Fuzzy sets, Inform. Control. 8, 338-353.

48 Ja'fari A., Kadkhodaie-Ilkhchi A., Sharghi Y., Ghaedi M. (2014) Integration of adaptive neuro-fuzzy inference system, neural networks and geostatistical methods for fracture density modeling, Oil Gas Sci. Technol. - Rev. IFP 69, 1143-1154.

49 Ghatee M., Hashemi S.M. (2009) Optimal network design and storage management in petroleum distribution network under uncertainty, Eng. Appl. Artif. Intell. 22, 806-817.

$50 \mathrm{Hu}$ Z., Chan C.W. (2015) In-situ bioremediation for petroleum contamination: a fuzzy rule-based model predictive control system, Eng. Appl. Artif. Intell. 38, 70-78.

51 Liao R.F., Chan C.W., Hromek J., Huang G.H., He L. (2008) Fuzzy logic control for a petroleum separation process, Eng. Appl. Artif. Intell. 21, 835-845.

52 Mohaghegh S. (2000) Virtual-intelligence applications in petroleum engineering: Part 3-Fuzzy logic, J. Petrol. Technol. 52, 82-87.

53 Khatami H.R., Ranjbar M., Schaffie M., Emadi M.A. (2008) Prediction of calcium carbonate precipitation in oilfields based on a fuzzy solubility model, Oil Gas-Eur. Mag. 34, 78-83.

54 Nashawi I.S., Malallah A. (2009) Improved electrofacies characterization and permeability predictions in sandstone reservoirs using a data mining and expert system approach, Petrophysics 50, 250-268.

55 Nowroozi S., Ranjbar M., Hashemipour H., Schaffie M. (2009) Development of a neural fuzzy system for advanced prediction of dew point pressure in gas condensate reservoirs, Fuel Process. Technol. 90, 452-457.

56 Jeirani Z., Mohamed Jan B., Si Ali B., Noor I.M., See C.H., Saphanuchart W. (2013) Formulation, optimization and application of triglyceride microemulsion in enhanced oil recovery, Ind. Crops Prod. 43, 6-14.

57 Jeirani Z., Mohamed Jan B., Si Ali B., Noor I.M., See C.H., Saphanuchart W. (2013) Prediction of the optimum aqueous phase composition of a triglyceride microemulsion using response surface methodology, J. Ind. Eng. Chem. 19, 1304-1309.

58 Jeirani Z., Mohamed Jan B., Si Ali B., Noor I.M., See C.H., Saphanuchart W. (2013) Formulation and phase behavior study of a nonionic triglyceride microemulsion to increase hydrocarbon production, Ind. Crops Prod. 43, 15-24.

59 Anderson M.J., Whitcomb P.J. (2004) RSM Simplified: Optimizing Processes using Response Surface Methods for Design of Experiments, Productivity Press.
60 Zahedzadeh M., Karambeigi M.S., Roayaei E., Emadi M.A., Radmehr M., Gholamianpour H., Ashoori S., Shokrollahzadeh S. (2014) Comprehensive management of mineral scale deposition in carbonate oil fields - a case study, Chem. Eng. Res. Des. 92, 2264-2272.

61 Van Den Bergh F., Engelbrecht A.P. (2006) A study of particle swarm optimization particle trajectories, Inform. Sci. 176, 937-971.

62 Raphael B., Smith I.F.C. (2003) A direct stochastic algorithm for global search, Appl. Math. Comput. 146, 729-758.

63 Mathews B.P., Diamantopoulos A. (1994) Towards a taxonomy of forecast error measures a factor-comparative investigation of forecast error dimensions, J. Forecast. 13, 409-416.

64 Shcherbakov M.V., Brebels A., Shcherbakova N.L., Tyukov A. P., Janovsky T.A., Kamaev V.A. (2013) A survey of forecast error measures, World Appl. Sci. J. 24, 171-176.

65 Chai T., Draxler R.R. (2014) Root mean square error (RMSE) or mean absolute error (MAE)? Arguments against avoiding RMSE in the literature, Geosci. Model. Dev. 7, 1247-1250.

66 Goodwin P., Lawton R. (1999) On the asymmetry of the symmetric MAPE, Int. J. Forcast. 15, 405-408.

67 Makridakis S., Hibon M. (2000) The M3-competition: Results, conclusions and implications, Int. J. Forcast. 16, 451-476.

68 Tadros T.F. (2013) Emulsion Formation, Stability, and Rheology, In: Emulsion Formation and Stability, Wiley, Weinheim, Germany, pp. 1-75.

69 Deng S., Wang Y., Hu Y., Ge X., He X. (2013) Integrated petrophysical log characterization for tight carbonate reservoir effectiveness: A case study from the Longgang area, Sichuan Basin, China, Pet. Sci. 10, 336-346.

70 Gundogar A.S., Ross C.M., Akin S., Kovscek A.R. (2015) Multiscale pore structure characterization of Middle East carbonates, J. Pet. Sci. Eng., in press, DOI:17.10.1016/ j. petrol.2016.1007.1018.

71 Zhao H., Ning Z., Wang Q., Zhang R., Zhao T., Niu T., Zeng Y. (2015) Petrophysical characterization of tight oil reservoirs using pressure-controlled porosimetry combined with ratecontrolled porosimetry, Fuel 154, 233-242.

72 Øren P.E., Bakke S. (2003) Reconstruction of Berea sandstone and pore-scale modelling of wettability effects, J. Pet. Sci. Eng. 39, 177-199.

73 Etris E.L., Brumfield D.S., Ehrlich R., Crabtree S.J. (1988) Relations between pores, throats and permeability: a petrographic/physical analysis of some carbonate grainstones and packstones, Carbonates Evaporites 3, 17-32.

74 Ausbrooks R., Hurley N.F., May A., Neese D.G. (1999) Poresize distributions in vuggy carbonates from core images, NMR, and capillary pressure. SPE Paper 56506, Presented at SPE Annual Technical Conference and Exhibition, Houston, Texas. 